Jeremias C. Zill, Marcel Kansy, Reimund Goss, Lisa Köhler, A. Alia, Christian

Wilhelm, Jörg Matysik. ${ }^{* 1}$

\title{
Photo-CIDNP in the reaction center of the diatom Cyclotella meneghiniana observed by ${ }^{13} \mathrm{C}$ MAS NMR
}

\author{
The solid-state photo-CIDNP effect in a new kingdom of the tree of life
}

\begin{abstract}
Photo-CIDNP MAS NMR presents a unique tool to obtain insight into the photosynthetic reaction centers (RCs) of bacteria and plants. Using the dramatic enhancement of sensitivity and selectivity of the solid-state photoCIDNP effect, structural as well as functional information can be obtained from the cofactor molecules forming a light-induced spin-correlated radical pair (SCRP) in a given reaction center. Here we demonstrate that the effect can be observed in a further species, which belongs neither to the plant nor the bacteria kingdom. Cyclotella (C.) meneghiniana is a member of the diatom phylum and, therefore, belongs to the kingdom of chromista. Chromista are some of the most productive organisms in nature, even in comparison to trees and terrestrial grasses. The observation of the effect in chromista indicates that the effect occurs in all photosynthetic organisms and completes the list with the last phototrophic kingdoms. Our data also demonstrate that the photo- and spin-chemical machineries of photosystem I of plants and chromista are very similar with respect to structure as well as function.
\end{abstract}

Keywords: Photo-CIDNP MAS NMR, Diatoms, Cyclotella meneghiniana

\section{Introduction}

The solid-state photo-CIDNP effect is a spin-chemical effect in which transiently nuclear spin order far from Boltzmann equilibrium occurs, which can be detected by solid-state NMR methods as modification of the equilibrium signal intensity. The NMR chemical shifts of the light-induced signal remain unchanged and thus provide access to the electronic ground-state structure of the electron donor and acceptor forming a spin-correlated radical pair (SCRP). In addition, the light-induced enhanced NMR intensities are related to the local electron spin densities in the electron donor and the electron acceptor forming the SCRP.[1][2] Selective ${ }^{13} \mathrm{C}$ isotope labeling at different positions in the cofactors of bacterial RCs revealed insight into the special pair and its electronic ground-state structure.[3][4] The underlying spin-dynamics (Scheme 1) of the well-known radical pair mechanisms (RPM)[5][6][7] leads to transient light-induced nuclear polarization which can be observed in time-resolved experiments.[8] Under continuous illumination, up to three spin-chemical mechanisms running in parallel have been revealed contributing to the photo-chemically induced dynamic polarization (photo-CIDNP) in the solid state in photosynthetic RCs: the three spin mixing (TSM), the differential decay (DD) and the differential relaxation (DR) mechanisms.[9][10][11][12]

Photosynthesis is a photochemical process that is initiated by the light-induced electron transfer in a photosynthetic reaction center (RC). There are two types of photosynthetic RCs that can be found in nature. The type-I RCs contain iron-sulfur clusters as terminal electron acceptors. Photosystem I (PS I) is such a type-I RC which is found in higher plants, eukaryotic algae and cyanobacteria. The type-I RCs found in bacteria, e.g. in the green sulfur bacteria (as chlorobium) and heliobacteria, work in analogy to this system. Type-I RCs have the tendency to provide strong reductive forces which, in PS I, are required for the reduction of NADP ${ }^{+}$. Type-II RC, such as that of the purple bacterium Rhodobacter (R.) sphaeroides, use quinone molecules as electron acceptors. The type-II RC of plants, algae and cyanobacteria, called photosystem II (PS II), has a very strong oxidative force which enables the oxidation of $\mathrm{H}_{2} \mathrm{O}$.

Photo-CIDNP magic-angle spinning (MAS) NMR provides direct access to the primary photosynthetic machinery in the RCs by yielding structural and functional information on the donor and acceptor cofactors forming the primary

\footnotetext{
1 *Corresponding author: Jörg Matysik, University of Leipzig, Institute of Analytical Chemistry, Johannisallee 29, D-04103 Leipzig, Germany, e-mail:joerg.matysik@uni-leipzig.de

Jeremias C. Zill and Lisa Köhler: University of Leipzig, Institute of Analytical Chemistry, Johannisallee 29, D-04103 Leipzig, Germany, Marcel Kansy, Reimund Goss and Christian Wilhelm: University of Leipzig, Institute of Biology, Abteilung Pflanzenphysiologie, Johannisallee 21-23, D-04103 Leipzig, Germany,

A. Alia: University of Leiden, Leiden Institute of Chemistry, Einsteinweg 55, P.O. Box 9502, 2300 RA Leiden, The Netherlands, University of Leipzig, Institute of Medical Physics and Biophysics, Härtelstr. 16-18, D-04107 Leipzig, Germany.
} 
SCRP. These cofactors are (bacterio)chlorophylls and (bacterio)pheophytins. In plants, the donor is formed by chlorophyll $a(\mathrm{Chl} a)$.

So far, there are eight species in which the solid-state photo-CIDNP effect has been observed (Figure 1, Table 1). These are all members of either the plant or the bacteria kingdom. According to the taxonomic classification of Cavalier-Smith[13], there are six kingdoms: animalia, plantae, chromista, fungi, bacteria and protozoa. Among them, three contain phototrophic members: the kingdoms of plantae, of chromista and of bacteria. The solid-state photo-CIDNP effect has been discovered in the kingdom of bacteria from the proteobacterium Rhodobacter sphaeroides in 1994 by Zysmilich and McDermott.[14] Another proteobacterium: Rhodopseudomonas acidophilia [15] has been demonstrated to show the effect as well as Chlorobium tepidum[16] from the chlorobi phylum, Synechocystis sp. PCC 6803[17] - a cyanobacterium - and the firmicute Heliobacillus mobilis.[18] Additionally, there are two more bacterial phyla which contain phototrophic members: chloroflexi and acidobacteria.[19] From both phyla, no experiments with photoCIDNP MAS NMR have been reported so far. The effect is not limited to bacterial RCs but is also observed in RCs of plants, e.g., Spinacia oleracea[20][21][22] and Spirodella oligorrhiza.[23] Furthermore, it was demonstrated, that photo-CIDNP can also be observed in the C57S-mutant of phototropin LOV1[24] from the green alga Chlamydomonas rheinhardtii. This blue-light photoreceptor is presently the only non-photosynthetic system demonstrated to show the effect. Until now, all attempts to show the effect in artificial donor-acceptor dyads failed. The fact that the solid-state photo-CIDNP effect can be observed in a variety of phyla, supports the idea that the effect might be an intrinsic property of photosynthetic RCs.[25] Therefore, it has been assumed that the effect is of functional relevance.[26]

Diatoms (phylum bacillariophyta) are a group of wide-spread eukaryotic algae, which occur either unicellular or live in colonies.[27] This phylum belongs to the kingdom of chromista,[13][28] where the solid-state photo-CIDNP effect has not yet been investigated. Originally, diatoms received attention for the very impressive diversity of shapes.[29] They possess a silicified cell wall and became, therefore, model organisms for studying bio-mineralization processes.[30] Based on their geometry, diatoms are divided into three classes: the pennate bacillariophyceae and two centric classes named coscinodiscophyceae and mediophyceae.[31][32] The latter one comprises the species $C$. meneghiniana which we use in the present work as candidate for the investigation of the solid-state photo-CIDNP effect because of the availability of biochemical methods for the isolation of intact photosystems from the cells. [33] A microscopic picture of C. meneghiniana is shown in Figure 2. Hence, our first aim is to test whether the solid-state photo-CIDNP effect can also be demonstrated in a member of the chromista kingdom.

The total net primary production of plants on earth is estimated to be in the dimension of ca 105 billion tons of carbon per year. Phytoplankton formed by diatoms, cyanobacteria, green algae and other photoautotrophs contribute more than $40 \%$ to this amount.[34] As a consequence of their abundance in the highly productive parts of the oceans, diatoms are estimated to contribute about 20 to $25 \%$ to the global net primary biomass production.[35] Beyond the function of $\mathrm{CO}_{2}$ binding, phytoplankton sediments to deeper sea levels where its decomposition by heterotrophic organisms leads to an inverse $\mathrm{CO}_{2}$ gradient. As a result, in the upper sea layers $\mathrm{CO}_{2}$ gets depleted. The concentration is eventually restored by $\mathrm{CO}_{2}$ uptake from the atmosphere.[36][37][38] This effect is called "organic carbon pump". Because of their importance for the marine ecosystem the investigation of the diatom photosynthesis with the help of photo-CIDNP MAS NMR is an important task. Therefore, after the demonstration of the solid-state photo-CIDNP effect in diatoms, further studies are intended to investigate in closer detail whether the diatom RCs represent specially tuned RCs.

Like the higher plants, green algae and cyanobacteria, chromista contain both PS I and PS II. The protein subunits of the core complexes of PS I and PS II are highly conserved for cyanobacteria and all eukaryotic phototrophs including the chromista.[39][40][41] The PS I is present as a monomer in the thylakoid membrane and contains 19 protein subunits. PsaA $(82 \mathrm{kDa})$ and $\mathrm{PsaB}(83 \mathrm{kDa})$ represent the two central protein subunits.[42] In the PS I core complex, the PsaA and PsaB subunits bind the reaction center Chl a molecules, including the central two cofactors forming the structural donor dimer, also called P700, as well as the two symmetric branches, of cofactors forming the electron transfer pathways. In addition, the PsaA and PsaB subunits also act as inner antenna and, thus, bind about $100 \mathrm{Chl}$ and about $20 \beta$-carotene molecules.[43][44][45][46]

While RCs appear to be conserved, their embedding varies significantly. In higher plants and some green algae, PS I is preferentially being found in the stroma thylakoids, while PS II is mainly located in the grana thylakoids.[47] In contrast to PS I PsbA and PsbD with the reaction center Chl a molecules P680 form the RC, whereas PsbB and PsbC with their associated $\mathrm{Chl} a$ and b-carotene molecules form the inner antenna.[47] In contrast to higher plants, bacillariophyta show no distinction between stroma and grana thylakoids and the thylakoid membranes are arranged in stack of three.[48][49][50] Also the antenna systems are entirely different between species: there are cyanobacterial phycobilisomes, membrane integral fucaxanthin enriched fucoxanthin chlorophyll $a / c$ binding proteins (FCPs) of the diatoms 
and brown algae as well as light-harvesting complexes II (LHCIIs) of green algae and higher plants (for a recent review see [51]). In diatoms also the silicate cell walls vary extremely in their architectures. The different embedding of PS I core raises the question whether it reflects differences on the microscopic scale. Thus, it is the aim of the present study to explore whether the effect still occurs in the isolated diatom RCs. Furthermore, if it occurs, possible differences in the isolated PS I of plants and chromista, using C. meneghiniana as example, will be investigated.

\section{Materials and Methods}

\subsection{Sample Preparation}

The diatom C. meneghiniana (1020-1a; Sammlung von Algenkulturen SAG Göttingen) was grown as a batch culture in $20 \mathrm{~L}$ of sterile filtered artificial sea water prepared according to the procedure of North Pacific Culture Collection for $21 \mathrm{~d}$.[52] Cultivation was done at $18{ }^{\circ} \mathrm{C}$ with a light-dark regime of $14 / 10 \mathrm{~h}$ with a light intensity of $100 \mu \mathrm{mol}$ photons $\mathrm{m}^{-2} \mathrm{~s}^{-1}$. To avoid sedimentation, the algal cultures were constantly stirred from the top.

After harvesting the algal cells by centrifugation at $2.000 \mathrm{~g}$ and $4^{\circ} \mathrm{C}$ for $7 \mathrm{~min}$ (Varifuge $3.0 \mathrm{R}$, Heraeus, Germany), diatom thylakoid membranes were prepared according to Lepetit et al.[33] The thylakoids were diluted to a total chlorophyll (Chl) concentration of $0.5 \mathrm{mg} / \mathrm{mL}$ and membrane solubilization was initiated by addition of $\mathrm{n}$-dodecyl $\beta$ D-maltoside (DM)(Roth, Germany) at a detergent/Chl ratio of 20 and a final detergent concentration of $1 \%(w / v)$. After the solubilization, which was performed in darkness on ice for $20 \mathrm{~min}$ under gentle stirring, non-solubilized material was removed by centrifugation at $10.000 \mathrm{~g}$ for $20 \mathrm{~min}$ (Allegra 64R, Beckman, USA). The solubilized pigment-protein complexes in the supernatant were immediately loaded onto linear sucrose density gradients $(0.1$ to $1 \mathrm{M}$ sucrose in thylakoid isolation medium B supplemented with $0.03 \% \mathrm{DM}$ )[33] followed by ultracentrifugation at $120,000 \mathrm{~g}$ for $17 \mathrm{~h}$ at $4^{\circ} \mathrm{C}$ (Optima C90 with SW28 rotor, Beckman, USA). After ultracentrifugation the PS I containing band was collected from the sucrose gradient and characterized by absorption spectroscopy and gel electrophoresis. Gel electrophoresis was performed according to Laemmli [53], using a $15 \%$ separating and a $4 \%$ stacking gel. Figure 3 shows the SDS-PAGE of the polypeptide composition of solubilized PS I complexes from C. meneghiniana. A total amount of $1.5 \mu \mathrm{g} \mathrm{Chl} \mathrm{was} \mathrm{applied} \mathrm{to} \mathrm{the} \mathrm{gel.} \mathrm{Assignment} \mathrm{of} \mathrm{the} \mathrm{reaction} \mathrm{centre} \mathrm{proteins} \mathrm{(PsaA} \mathrm{and} \mathrm{PsaB)} \mathrm{and}$ two additional small subunits (PsaD and PsaL) was done by comparing the band pattern with published data.[33] Further PSI proteins (molecular weight range $\sim 3 \mathrm{kDa}$ up to $10 \mathrm{kDa}$ ) are not resolved with the applied experimental setup but are likely present in a broad band below the $12.5 \mathrm{kDa}$ marker protein (not shown). Additional bands in the range from $36 \mathrm{kDa}$ to $55 \mathrm{kDa}$ are probably due to slight contamination of the PSI core complexes with proteins of the $\mathrm{CF}_{1}$ part of the ATP-synthase complex. Absorption spectra of PS I complex (equivalent to a Chl concentration of $5 \mu \mathrm{g} / \mathrm{mL}$ ) were recorded in the wavelength range from 350 to $750 \mathrm{~nm}$ using a Specord M250 spectrophotometer (Zeiss, Germany). Figure 4 shows the absorption spectra of solubilized PS I core complexes from the green plant S. oleracea and the diatom C. meneghiniana. Both spectra show the typical absorption features of the main pigment Chl $a$ as indicated by the absorption maxima in the blue (438 nm in both spectra) and the red part (675 $\mathrm{nm}$ for C. meneghiniana and $678 \mathrm{~nm}$ for S. oleracea) of spectrum. The different red absorbing features are due to a population of long-wavelength absorbing Chl $a$ molecules in the PS I antenna (LHCI) which stays attached to the spinach PS I core complexes after the preparation. The presence of a small amount of LHCI is also evident from the additional absorption at $471 \mathrm{~nm}$ which is caused by $\mathrm{Chl} b$. The absorption around $489 \mathrm{~nm}$ in both the PSI core complex from S. oleracea and C. meneginiana depicts the presence of $\beta$-carotene in both PS I reaction centers.

For NMR measurements the PS I containing sample was concentrated in Centricon plus 20 centrifugal filter devices (Millipore Corporation, Bedford, USA, Amicon, $30 \mathrm{kDa}$ molecular weight cutoff) by centrifugation at $3.500 \mathrm{~g}$ and $4{ }^{\circ} \mathrm{C}$. Before NMR measurement, the iron-sulfur clusters $F_{B}$ and $F_{A}$ in PS I have been reduced by addition of aqueous $1 \mathrm{M}$ sodium dithionite solution to a final concentration of $100 \mathrm{mM}$ in an oxygen free atmosphere.[20]

\subsection{MAS-NMR Measurements}

All NMR spectra were obtained using an Avance III 400-MHz wide-bore NMR spectrometer equipped with a $4 \mathrm{~mm}$ MAS probe. The sample was loaded into a 4-mm sapphire rotor and inserted into the MAS probe. The temperature was decreased slowly to ensure homogeneous sample distribution against the rotor wall.[54] Light and dark spectra were acquired using a Hahn-echo pulse sequence with two-pulse phase modulation (TPPM) proton decoupling.[55] ${ }^{13} \mathrm{C}$ 
MAS NMR spectra were collected at a temperature of $250 \mathrm{~K}$ with a deviation of approximately $2 \mathrm{~K}$ and under continuous illumination with white light using a 1000-W xenon-arc lamp.[56] Calibration of the sample temperature was carried out by measuring the melting points of different substances (distilled water, 4-decanone and 3-octanone) followed by the correlation with the ${ }^{207} \mathrm{~Pb}$ chemical shift of a solid powder of lead nitrate measured at the according temperatures. [57][58] The MAS rotational frequency was $8 \mathrm{kHz}$ and the cycle delay was $4 \mathrm{~s}$. A line broadening of $5 \mathrm{~Hz}$ was applied before Fourier transformation. All ${ }^{13} \mathrm{C}$ MAS NMR spectra were referenced using the ${ }^{13} \mathrm{COOH}$ resonance of solid cationic histidine $\cdot \mathrm{HCl}$ at $173.2 \mathrm{ppm} .[59]$

\section{Results and Discussion}

\subsection{Photo-CIDNP ${ }^{13} \mathrm{C}$ MAS NMR spectra of C. meneghiniana}

Figure 5 shows the ${ }^{13} \mathrm{C}$ MAS NMR spectra of PS I core complexes of $C$. meneghiniana in the dark (A) and under continuous illumination with white light (B) at a magnetic field of $9.4 \mathrm{~T}$ (400 $\mathrm{MHz}{ }^{1} \mathrm{H}$ frequency). Both spectra were collected over 3 days with a number of scans of about 65,000 . Between 0 and $100 \mathrm{ppm}$ the characteristic ${ }^{13} \mathrm{C} N M R$ signals of a protein can be observed in the dark spectrum (A). The sharp absorptive response at 104.3 ppm arises from the 2-( $N$-morpholino)ethansulfonic acid (MES) that was present in the buffer. In spectrum B, which was obtained under continuous illumination, in addition to the signals observed in the dark, a number of emissive (negative) lightinduced signals appear. This is the first time that the solid-state photo-CIDNP effect is observed in the taxonomic kingdom of chromista (Figure 1). Therefore, in all three kingdoms containing photosynthetic species the effect is conserved, and it is reasonable to assume that the solid-state photo-CIDNP effect is an inherent property of photosynthetic systems.

Figure 6 presents a detailed view on the spectral area showing the light-induced signals. Fourteen light-induced signals are observed in the range of carbonylic, aromatic and methine carbon chemical shifts. As expected, no solidstate photo-CIDNP is observed in the aliphatic region because aliphatic carbons do not contain local electron spin density in $\mathrm{p}_{z}$ orbitals. [60] The signal at $192.0 \mathrm{ppm}$ originates from a carbonyl resonance, there is a number of twelve resonances identified in the aromatic region, and also one signal, at $105.9 \mathrm{ppm}$ originates from a methine carbon. The fact that only one carbonylic and only one methine resonance occur implies that a single "monomeric" cofactor is observed.

In the photo-CIDNP MAS NMR spectrum of the PS I core complexes of C. meneghiniana, all light-induced signals are emissive. The emissive sign of the signals can be explained by the TSM mechanism which has been shown for RCs of $R$. sphaeroides wild type (WT) to lead to emissive signals.[61][62] Also entirely emissive spectra have been observed on PS I particles of Spinacia oleracea (spinach).[20] In contrast, RCs of R. sphaeroides R26[9][62] and PS II (D1/D2 preparation) of spinach[22] show enhanced absorptive signals of the aromatic carbons together with the emissively polarized methine carbons. In these samples, due to the absence of carotenes in the vicinity of the donor, long donor triplet lifetimes, and therefore the DR mechanism can occur. Hence, the spectral pattern observed in PS I of $C$. meneghiniana, composed of emissive light-induced signals only, suggests the presence of carotenes sufficiently close to the donor allowing to quench molecular triplet states. The protein complex contains $20 \beta$-carotene molecules.[43][44][45][46] The x-ray structure of PS I of pea (4XK8.pdb)[63] shows a center-to-center distance of a P700 magnesium to the closest $\beta$-carotene molecule of $14.4 \AA$. The minimal edge-to-edge distance of P700 to the carotene is $10.6 \AA$. The situation in the bacterial RC of $R$. sphaeroides WT (1M3X.pdb)[64] is rather similar: The distance of the special pair magnesium to the closest carotene is $14.4 \AA$ center-to-center and $8.6 \AA$ edge to edge.

In quinone-blocked bacterial RCs, the lifetime of the donor triplet state is $100 \mathrm{~ns}$ for WT samples, where the DR mechanism has not been observed, and $100 \mu$ s for the carotene-less mutant R26, where strong DR is observed.[9] The efficiency of the DR mainly depends on the longitudinal relaxation time, which must be in the range of a few hundred nanoseconds or a couple of microseconds. It strongly depends on the Zeeman field $\mathrm{B}_{0}$, the temperature and in that temperature range possibly occurring glass transitions. Since the donor-carotene distance is slightly larger in plant PS I than in the case of bacterial $\mathrm{RC}$, it can be assumed that the quenching of the molecular donor triplet state is less efficient in eukaryotic PS I. In fact, data shown by Sétif and Brettel[65] presented a half-life of $5 \mu$ s for the molecular donor triplet state ${ }^{3} \mathrm{P} 700$ for a plant PS I of spinach. It appears that $5 \mu$ s are close to the condition allowing to make the DR operative. Therefore, assuming that the observed signals originate from the donor (see below), it might be that in PS I the DR already weakens the emissive intensities caused by the TSM. Such assumption would also explain the 
field dependence of the solid-state photo-CIDNP effect in PS I samples showing an optimum at about 9.4 T (400 MHz ${ }^{1} \mathrm{H}$ frequency)[22] since the DR has been shown to be particularly efficient at lower fields.[62]

\subsection{Signal assignments}

Table 2 provides an overview of the resonances enhanced by the solid-state photo-CIDNP effect and compares the present experimental data with chemical shifts observed in PS I of Spinacia oleracea[20] and on pure Chl $a$ in a solid aggregate.[66] The most deshielded light-induced signal (Figure 6) appears at $192.0 \mathrm{ppm}$ in the carbonyl region and matches well to the carbon $\mathrm{C}-13^{1}$ on ring $\mathrm{V}$ (for numbering see Figure 7) The strongest signals appear in the aromatic region. The signal at $168.2 \mathrm{ppm}$ is very likely to originate from carbon C-19. The resonance at $161.2 \mathrm{ppm}$ is reasonably assigned to carbon C-14. Probably, both the carbons C-1 and C-6 contribute to the signal at $156.1 \mathrm{ppm}$, while carbon C-16 yields the signal at $153.6 \mathrm{ppm}$. Carbon C-4 matches well to the signal at $151.4 \mathrm{ppm}$. The strongest lightinduced response at $148.4 \mathrm{ppm}$ is conveniently assigned to carbons C-9 and C-11. This signal shows a shoulder at $147.8 \mathrm{ppm}$ which might also be attributed to one or both of these carbons. Carbon C-8 is then assigned to $145.5 \mathrm{ppm}$. The resonance at $139.8 \mathrm{ppm}$ might be due to carbon C-3. The two weak features at $137.9 \mathrm{ppm}$ and $133.4 \mathrm{ppm}$ could be assigned to carbon C-2 as well as carbons C-7 or C-13, respectively. The signal at $135.7 \mathrm{ppm}$ can be attributed to carbon $\mathrm{C}-12$. In the region of methine carbons, the response at $105.9 \mathrm{ppm}$ can be assigned to either $\mathrm{C}-10$ or $\mathrm{C}-15$. Hence, all light-induced signals can be assigned very conveniently to a single $\mathrm{Chl} a$ cofactor.

The single Chl $a$ cofactor detected in the photo-CDINP MAS NMR experiment might be belonging to the P700 donor. In contrast to many other RCs carrying a (bacterio)pheophytin as primary acceptor, in PS I the acceptor is a plant Chl $a$ cofactor, too. Therefore, we cannot conclusively decide whether the signal is obtained from the donor or the acceptor site. Previous experiments, however, revealed that the light-induced photo-CIDNP MAS NMR signals mainly originate from the donor site.[20] Therefore, we tentatively assign the observed signals to a Chl $a$ at the P700 donor site. This assignment implies that the P700 donor acts essentially as a functional monomer. Since, we cannot rule out that a set of signals of a second cofactor is hidden in the noise, we certainly can conclude that at least $85 \%$ of the electron spin density at the donor site is located on a single Chl $a$ cofactor. The conclusion of monomeric donor is well in line with EPR studies on PS I of various organisms: While earlier EPR studies concluded that the donor in PS I acts as a monomer with at least $85 \%$ of the electron-spin density on a single cofactor[67][68][69], later advanced EPR studies suggested a small fraction of electron spin density on another site [70][71] (for review, see [72]).

The donor of PS I in plants is known to be a structural dimer formed of a normal plant Chl $a$ and a second Chl $a$ ' which is epimerized at the $\mathrm{C} 13^{2}$ position.[43][73][74] Since ${ }^{13} \mathrm{C}$ chemical shifts of $\mathrm{Chl} a$ and Chl $a$ ' are very similar[75] it is hard to conclude from the present ${ }^{13} \mathrm{C}$ NMR data whether the observed chemical shifts are induced by the normal plant Chl $a$ or its epimer. Our data, however, provide a hint: The light-induced signal at 192.0 ppm, assigned to $\mathrm{C}-13^{1}$, is more close to the literature value for Chl $a(190.6 \mathrm{ppm})$ than to the value of Chl $a^{\prime}(189.5 \mathrm{ppm})$. Hence, our data suggest that the Chl $a$ cofactor and not the $\mathrm{Chl} a^{\prime}$ is observed. In any case, in the limits of signal-tonoise-ratio our data suggest that on the time-scale of our photo-CIDNP MAS NMR experiment, the donor acts as a monomer. Probably the electron spin density is localized on the normal Chl a cofactor, although the donor appears structurally to be a dimer.

Since ${ }^{13} \mathrm{C}$ solid-state photo-CIDNP intensities correlate to local electron spin densities[76], Figure 8 shows a reconstruction of the local electron spin density on the donor Chl $a$ which correlates with the HOMO orbital structure. Obviously, the HOMO is mainly localized on pyrrole rings II and IV.

\subsection{Lineshape and linewidth}

The lineshape of the observed signals is Lorentzian, although for the signals at $147.8 \mathrm{ppm}, 137.9 \mathrm{ppm}$ and $133.4 \mathrm{ppm}$ having low signal-to-noise ratio, no specific lineshape can be determined. For the light-induced resonances, a narrow linewidth of about $60 \mathrm{~Hz}$ is observed. The larger linewidth of the signals at $156.1 \mathrm{ppm}(105 \mathrm{~Hz})$ and $133.4 \mathrm{ppm}$ $(136 \mathrm{~Hz})$ can be explained by two overlapping signals. The signal $156.1 \mathrm{ppm}$ is attributed to the carbons C-1 and C-6, and the resonance at $133.4 \mathrm{ppm}$ is assigned to both C-7 and C-13. Hence, apparently all nuclei observed show linewidths of about $60 \mathrm{~Hz}$. The Lorentzian form as well as such narrow lines are demonstrating a structurally and electrostatically rigid donor without structural inhomogeneities. This conclusion also has been made for donor cofactors in other RCs[54] and correlates with the general rule that efficient electron transfer requires rigidity. 


\subsection{Comparison with PS I preparations from other species}

The ${ }^{13} \mathrm{C}$ solid-state photo-CIDNP effect has been already reported for PS I of several other systems: for core complexes of Spinacia oleracea[20] and for intact cells of the cyanobacterium Synechocystis sp.[17] Especially the similarity of the spectra reported in this work to those from S. oleracea[20] is remarkable. In the work on spinach, eleven lightinduced signals were observed and also assigned to a single Chl $a$ donor cofactor. The chemical shifts observed in the present study are similar which can be demonstrated, e.g., by the isolated carbonyl carbon $\mathrm{C}-13^{1}$ resonating at $192.0 \mathrm{ppm}$ in C. meneghiniana and at $190.6 \mathrm{ppm}$ in S. oleracea. Also the chemical shifts of the most deshielded aromatic carbon C-19 is observed at very close positions for C. meneghiniana (168.2 ppm) and spinach (167.1 ppm). As a last example, the signal which is attributed to the methine carbons C-10 or C-15 can be found at nearly the same frequency for C. meneghiniana (105.9 ppm) and spinach (105.4 ppm). The slightly different chemical shifts may reflect different buffers and detergents as well as the $\mathrm{pH}$ difference (pH 6.5 and DM for C. meneghiniana; $\mathrm{pH} 9.5$ and Triton $\mathrm{X}-100$ for Spinacia oleracea).[20]

Also the observed electron-spin density patterns from C. meneghiniana (Figure 8) and S. oleracea[20], summarizing the intensities, are very similar. In both cases, the HOMO is mainly localized on pyrrole rings II and IV implying an analogue orbital structure. Hence, our data proof that the functional machinery of these two PS I RCs is very similar and highly conserved although these species originate from different kingdoms and are characterized by significant thylakoid architectures.

The solid-state photo-CIDNP effect also has been observed in ${ }^{13} \mathrm{C}$-labeled samples of Synechocystis sp. on cells without further isolation at 4.7 T.[17] Eight light-induced signals have been observed but not assigned to the cofactors of either PS I or PS II. Since all light-induced signals are emissive, it was however assumed that they originate from PS I. In fact the signals appear at similar positions like in the case of C. meneghiniana or S. oleracea. In PS I of Synechocystis, the distance between donor and carotene is $14.7 \AA$ (center-to-center) and $10.7 \AA$ (edge-to-edge) (ref. 1JB0.pdb).[43] Hence, in all three systems both structure as well as functional mechanism is well maintained.

\section{Conclusions}

The solid-state photo-CIDNP effect has been observed in isolated PS I RCs (PS I core complex preparations) of the diatom C. meneghiniana by ${ }^{13} \mathrm{C}$ MAS NMR. This is the first time that the effect has been observed in a species from the taxonomic kingdom of chromista. Hence, the effect occurs in all three kingdoms containing photosynthetic species. This is remarkable because the occurrence of the effect is confined to very specific conditions.[26] The high conservation supports the idea that the effect is related to a comparable function of the electron steps in the early photosynthetic RCs.

All light-induced signals can be conveniently assigned to a single Chl $a$ cofactor. It is very likely that this Chl $a$ acts rather as donor than as acceptor. All signals appear emissively due to the presence of carotene cofactors in the vicinity. Lineshape and -width indicate a highly ordered rigid donor. Chemical shifts and intensity pattern are very similar to that observed from PS I of the higher plant Spinacia oleracea. PS I from both species seem to be very similar concerning their photochemical machinery and their spin dynamics. Hence, the highly efficient PS I [77] is highly conserved even if the entire embedding by the thylakoid membrane or the PSI-surrounding antenna systems varies significantly. This comes as a surprise because it was shown that the photosynthetic machinery of diatoms is integrated into a metabolic network which has a significantly different regulation compared to higher plants.[78] Obviously, the reaction centers had reached their physical optimum very early in the evolution. Consequently the selection pressure was high on the biological usage of the electrons but not on the site of their generation.

Acknowledgement: The authors thank a reviewer for hinting to ref. [65] and Dr. Matthias Findeisen for his technical support. Kind support of the DFG is acknowledged (MA 4972/2-1). 
Bibliography

[1] E. Daviso, G. Jeschke, J. Matysik, In: Biophysical Techniques in Photosynthesis, T. Aartsma, J. Matysik (eds.), Springer, Dordrecht, (2008), 385-399.

[2] G. Jeschke, J. Matysik, Chem. Phys. 294 (2003) 239-255.

[3] E.A.M. Schulten, J. Matysik. A. Alia, S. Kiihne, J. Raap, J. Lugtenburg, P. Gast, A.J. Hoff, H.J.M. de Groot, Biochemistry 41 (2002) 8708-8717.

[4] S. Prakash, Ph.D. Thesis, University of Leiden (2006) 91.

[5] G.L. Closs, J. Am. Chem. Soc. 91 (1969) 4552.

[6] R. Kaptein, L.J. Oosterhoff, Chem. Phys. Lett 4 (1969) 195.

[7] G.L. Closs, A.D. Trifunac, J. Am. Chem. Soc. 92 (1970) 2183.

[8] E. Daviso, A. Diller, P. Gast, A. Alia, J. Lugtenburg, M. G. Müller, J. Matysik, Appl. Magn. Res. 28 (2010) 105-106.

[9] S. Prakash, A. Alia, P. Gast, H.J.M. de Groot, J. Matysik, G. Jeschke, J. Am. Chem. Soc. 128 (2006) 12794-12799.

[10] G. Jeschke, J. Am. Chem. Soc. 120 (1998) 4425-4429.

[11] T. Polenova, A.E. McDermott, J. Phys. Chem. 103 (1999) 535-548.

[12] A. McDermott, M.G. Zysmilich, T. Polenova, Solid State Nucl. Magn. Reson. 11 (1998) 21-47.

[13] T. Cavalier-Smith, Biol. Rev. 73 (1998) 347-366.

[14] M.G. Zysmilich, A. McDermott, J. Am. Chem. Soc. 116 (1994) 8362-8363.

[15] A. Diller, A. Alia, P. Gast, G. Jeschke, J. Matysik, In: Photosynthesis. Energy from the sun. Springer, Dordrecht, 14th international Congress of Photosynthesis, (2008), 55-58.

[16] E. Roy, A. Alia, P. Gast, J.H. van Gorkom, H.J.M. de Groot, G. Jeschke, J. Matysik, Biochim. Biophys. Acta 1767 (2007) 610-615.

[17] G.J. Janssen, E. Daviso, M. van Son, H.J.M. de Groot, A. Alia, J. Matysik, Photosynth. Res. 104 (2010) 275-282.

[18] E. Roy, T. Rohmer, P. Gast, G. Jeschke, A. Alia, J. Matysik, Biochemistry 47 (2008) 4629-4635.

[19] D.A. Bryant, A.M. Garcia Costas, J.A. Maresca, A. Gomez Maqueo Chew, C.G. Klatt, M.M. Bateson, L.J. Tallon, J. Hostetler, W.C. Nelson, J.F. Heidelberg, D.M. Ward, Science 317 (2007) 523-526.

[20] A. Alia, E. Roy, P. Gast, H.J. van Gorkom, H.J.M. de Groot, G. Jeschke, J. Matysik, J. Am. Chem. Soc. 126 (2004) 1281912826.

[21] A. Diller, A. Alia, E. Roy, P. Gast, H.J. van Gorkom, J. Zaanen, H.J.M. de Groot, C. Glaubitz, J. Matysik, Photosynth. Res. 84 (2005) 303-308.

[22] E. Roy, A. Diller, A. Alia, P. Gast, H.J. van Gorkom, H.J.M. de Groot, G. Jeschke, J. Matysik, Appl. Magn. Res. 31 (2007) 193-204.

[23] G.J. Janssen, E. Roy, J. Matysik, A. Alia, Appl. Magn. Res. 42 (2012) 57-67.

[24] S.S. Thamarath, J. Heberle, P. Hore, T. Kottke, J. Matysik, J. Am. Chem. Soc. 132 (2010) 15542-.

[25] J. Matysik, A. Diller, E. Roy, A. Alia, Photosyn. Res. 102 (2009) 427-435.

[26] I. Cespedes Camacho, J. Matysik, In: "The Biophysics of Photosynthesis", J. Golbeck, A. van der Est (eds.),Springer (2014) 141-170.

[27] M. Sumper, E. Brunner, ChemBioChem 9 (2008) 1187-1194.

[28] T. Cavalier-Smith, J. Eukary. Microbiol. 46 (1999) 347-366.

[29] F.E. Round, R.M. Crawford, The Diatoms, Cambridge University Press (1990) 651.

[30] D. Wisser, S.I. Brückner, F.M. Wisser, G. Althoff-Ospelt, S. Kaskel, E. Brunner, Solid State Nucl. Magn. Reson. 66/67 (2015) 33-39.

[31] P.A. Sims, D.G. Mann, L.K. Medlin, Phycologia 45 (2006) 361-402.

[32] C. Bowler, A.E. Allen, J.H. Badger, J. Grimwood, K. Jabbari, A. Kuo, U. Maheswari, C. Martens, F. Maumus, R.P. Otillar, E. Rayko, A. Salamov, K. Vandepoele, B. Beszteri, A. Gruber, M. Heide, M. Katinka, T. Mock et al. Nature 456 (2008) 239-244.

[33] B. Lepetit, D. Volke, M. Szabó, R. Hoffmann, G. Garab, C. Wilhelm, R. Goss, Biochem. 46 (2007) 9813-9822.

[34] J.A. Wiens (ed.), F.B. Golley: Energy flux systems, Oregon State University press, Corvallis (1972) 69-88.

[35] D. Werner (ed.): The Biology of the diatoms, University of California, Blackwell Scientific Publications, (1977), 498.

[36] V. Smetacek, Protist 150 (1999) 25-32.

[37] S.W. Chrisholm, Nature 407 (2000) 685-687.

[38] R.J. Geider, E.H. Delucia, P.G. Falkowski, A.C. Finzi, J.P. Grime, J. Grace, T.M. Kana, J. La Roche, S.P. Long, B.A. Osborne, T. Platt, I.C. Prentice, J.A. Raven, W.H. Schlesinger, V. Smetacek, V. Stuart, et al. Global Change Biology 7 (2001) 849-882.

[39] B.R. Green, D.G. Durnford, Annual Review of Plant Physiology and Plant Molecular Biology 47 (1996) 685-714. 
[40] J. Barber, Biochemical Society Transactions 34 (2006) 619-631.

[41] B. Lepetit, Untersuchungen zur Struktur der Antennenkomplexe und zur Lokalisation der Xanthophyllzykluspigmente in Diatomeen, Dissertation: Universität Leipzig (2010) 184.

[42] A. Amunts, N. Nelson, Plant Physiology and Biochemistry 46 (2008) 228-237.

[43] P. Jordan, P. Fromme, H.T. Witt, O. Klukas, W. Saenger, N. Krauss, Nature 411 (2001) 909-917.

[44] A. Ben-Shem, F. Frolow, N. Nelson, Nature 426 (2003) 630-635.

[45] P.E. Jensen, R. Bassi, E.J. Boekema, J.P. Dekker, S. Janson, D. Leister, C. Robinson, H.V. Scheller, Biochim. Biophys. Acta-Bioenergetics 1767 (2007) 335-352.

[46] A. Amunts, O. Drory, N. Nelson, Nature 447 (2007) 58-63.

[47] J.P. Dekker, E.J. Boekema, Biochem. Biophys. Acta 1706 (2005) 12-39.

[48] S.P. Gibbs, Journal of Ultrastructure Research 7 (1962) 418-435.

[49] S.P. Gibbs, Annals of the New York Academy of Sciences 175 (1970) 454-473.

[50] A.M. Pyszniak, S.P. Gibbs, Protoplasma 166 (1992) 208-217.

[51] C. Büchel, J. Plant Physiol. 172 (2015) 62-75.

[52] P.J. Harrison, R.E. Waters, F.J.R. Taylor, Journal of Phycology 16 (1980) 28-35.

[53] U.K. Laemmli, Nature 227 (1970) 680-685.

[54] M.R. Fischer, H.J.M. de Groot, J. Raap, C. Winkel, A.J. Hoff, J. Lugtenburg, Biochemistry 31 (1992) 11038-11049.

[55] A.E. Bennett, C.M. Rienstra, M. Auger, K.V. Lakshmi, R.G. Griffin, J. Chem. Phys. 103 (1995) 6951.

[56] J. Matysik, Alia, J.G. Hollander, T. Egorova-Zachernyuk, P. Gast, H.J.M. de Groot, Indian J. Biochem. Biophys. 37 (2000) 418.

[57] A. Bielecki, D. B. Burum, Journal of the Magnetic Resonance, Series A 116 (1995) 215-220.

[58] W. M. Haynes (ed.): CRC Handbook of Chemistry and Physics, 95th Edition, Taylor \& Francis Ltd., CRC Press (2015) 3142.

[59] S. Hong and M. Li, J. Am. Chem. Soc. 133 (2011) 1534-1544.

[60] A. Diller, S. Prakash, A. Alia, P. Gast, J. Matysik, G. Jeschke, J. Phys. Chem. B 111 (2007) 10606-10614.

[61] S. Prakash, A. Alia, P. Gast, H.J.M. de Groot, G. Jeschke, J. Matysik, J. Am. Chem. Soc. 127 (2005) 14290-14298.

[62] S. S. Thamarath, B. E. Bode, S. Prakash, K. B. S. S. Gupta, A. Alia, G. Jeschke, J. Matysik, J. Am. Chem. Soc. 134 (2012) 5921-5930.

[63] X. Qin, M. Suga,T. Kuang,J.R. Shen, Science 348 (2015) 989-995.

[64] A. Camara-Artigas, D. Brune, J.P. Allen, Proc.Natl.Acad.Sci.USA 99 (2002) 11055-11060.

[65] P. Sétif, K. Brettel, Biochim. Biophys. Acta 1020 (1990) 232-238.

[66] G.J. Boender, University of Leiden, Ph.D. Thesis (1996).

[67] H. Käß, P. Fromme, H. Witt, W. Lubitz, Biophys. J. 66 (1994) A228.

[68] S.E.J. Rigby, J.H.A. Nugent, P.J. O'Malley, Biochemistry 33 (1994) 10043.

[69] H. Käß, E. Bittersmann-Weidlich, L.-E. Andréasson, B. Bönigkt, W. Lubitz, Chem. Phys. 194 (1995) 419.

[70] H. Käß, W. Lubitz, Chem. Phys. Lett. 251 (1996) 193.

[71] M. Mac, X.-S. Tang, B.A. Diner, J. McCracken, G.T. Babcock, Biochemistry 35 (1996) 13288-13293.

[72] Y. Deligiannakis, A.W. Rutherford, Biochim. Biophys. Acta 1507 (2001) 226-246.

[73] T. Watanabe, M. Kobayashi, A. Hongu, M. Nakazato, T. Hiyama, N. Murata, FEBS Lett. 191 (1985) 252-256.

[74] A.N. Webber, W. Lubitz, Biochim. Biophys. Acta 1507 (2001) 61-79.

[75] S. Lötjönen, P.H. Hynninen, Organic Magnetic Resonance 21 (1983) 757-765.

[76] A. Diller, S. Prakash, A. Alia, P. Gast, J. Matysik, G. Jeschke, J. Phys. Chem. B 111 (2007) 10606-10614.

[77] G.C. Papageorgiou, Govindjee, Chlorophyll a Fluorescence, Springer Science and Business Media, (2007) 820.

[78] C. Wilhelm, C. Büchel, J. Fisahn, R. Goss, T. Jakob, P. Kroth, J.Laroche, J. Lavaud, M. Lohr, U. Riebesell, K. Stehfest, K. ValeValentin, Protist 157 (2006) 91-124.

[79] M.D. Guiry, G.M. Guiry, 2016. AlgaeBase. World-wide electronic publication, National University of Ireland, Galway. http://www.algaebase.org; searched on 24 May 2016.

[80] G.J. Janssen: The Heart of Oxigenetic Photosynthesis illuminated, University of Leiden, Ph.D. Thesis (2013) 141.

[81] G. Jeschke, J. Matysik, Chemical Physics 294 (2003) 239-255. 


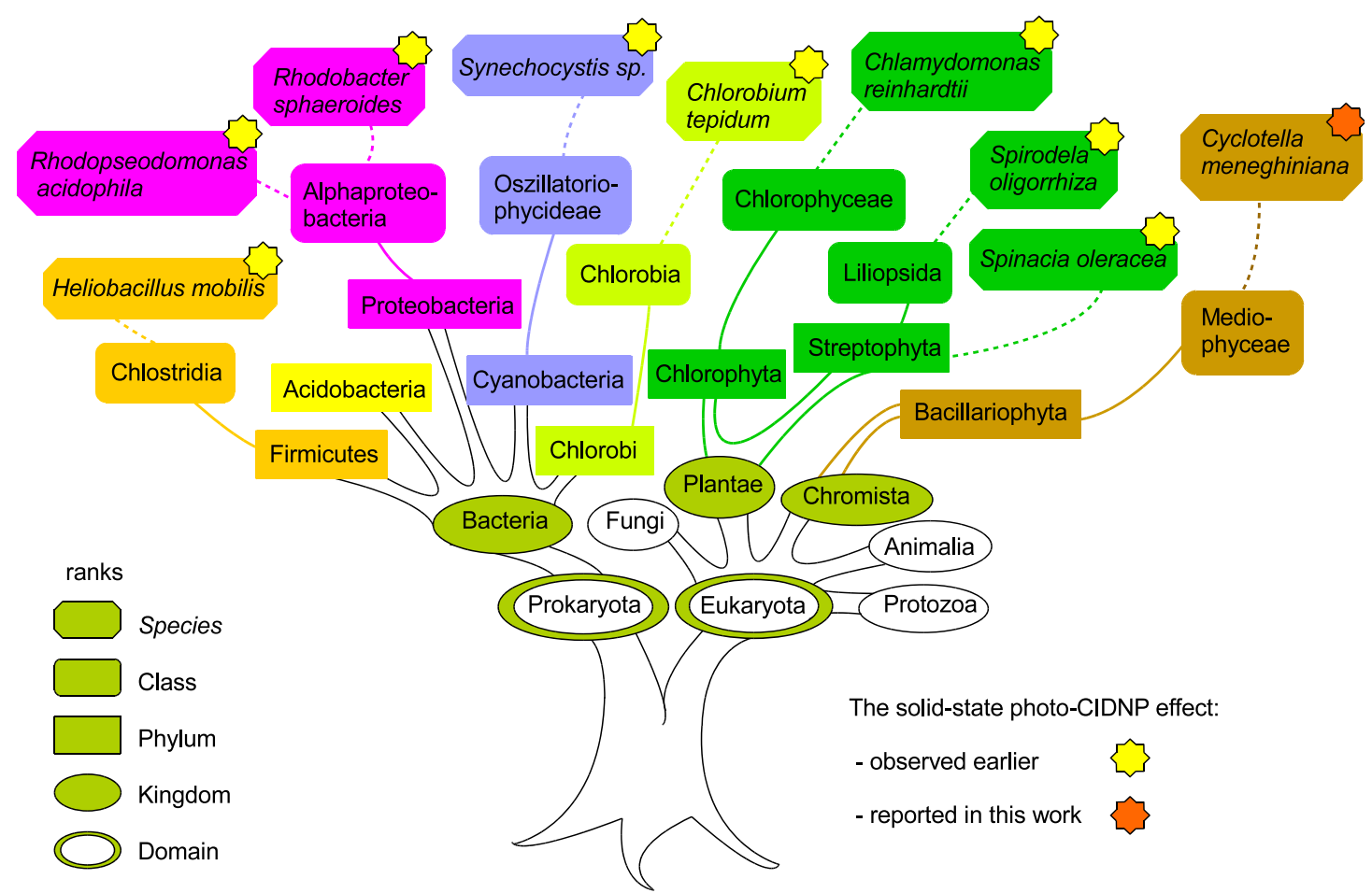

Figure 1: Tree of Life according to Cavalier-Smith,[13] modified. Selected kingdoms containing photosynthetically active species are labeled in green. Species demonstrated to show the solid-state photo-CIDNP effect are labeled with a star. In the present work, the occurrence of the solid-state photo-CIDNP effect is explored in the kingdom of chromista.

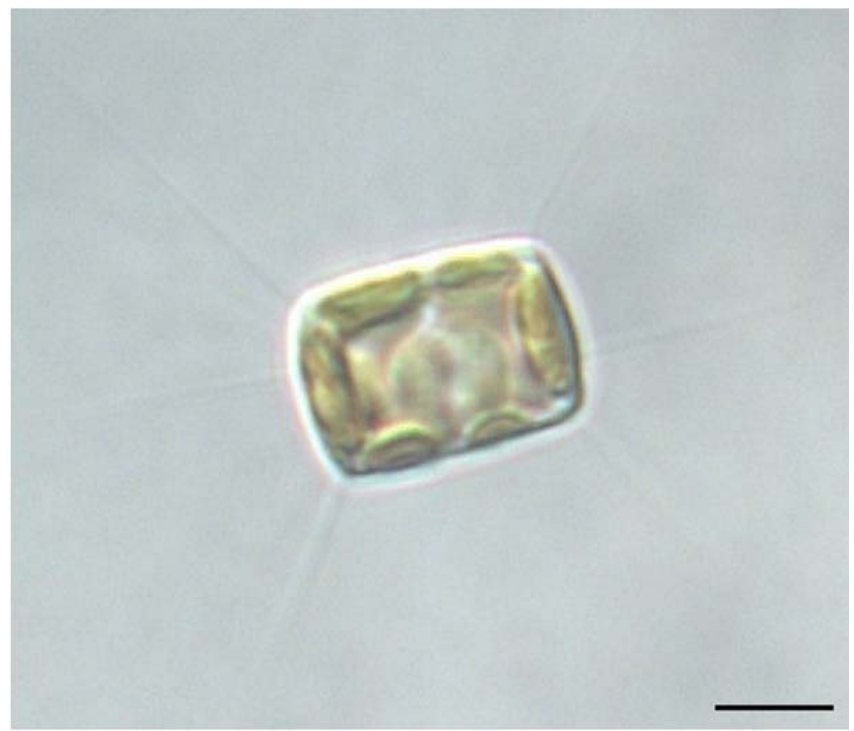

Figure 2: Cyclotella meneghiniana. Cellular nucleus (circle in the center), chloroplasts (oval organelles at the cell wall) and inorganic shell (white external border) can be well recognized. The length of the line is equal to $0.5 \mu \mathrm{m}$. 


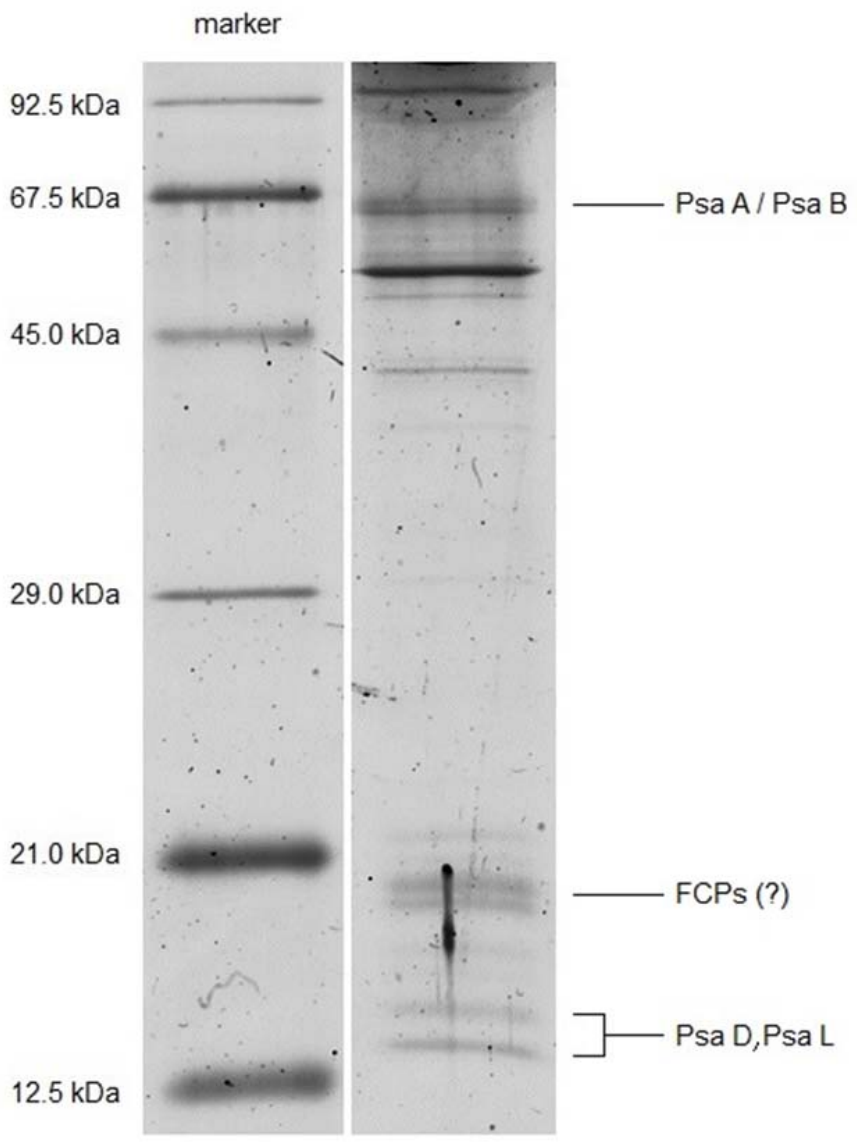

Figure 3: SDS-PAGE: Polypeptide composition of solubilized PS I complexes from C. meneghiniana. 


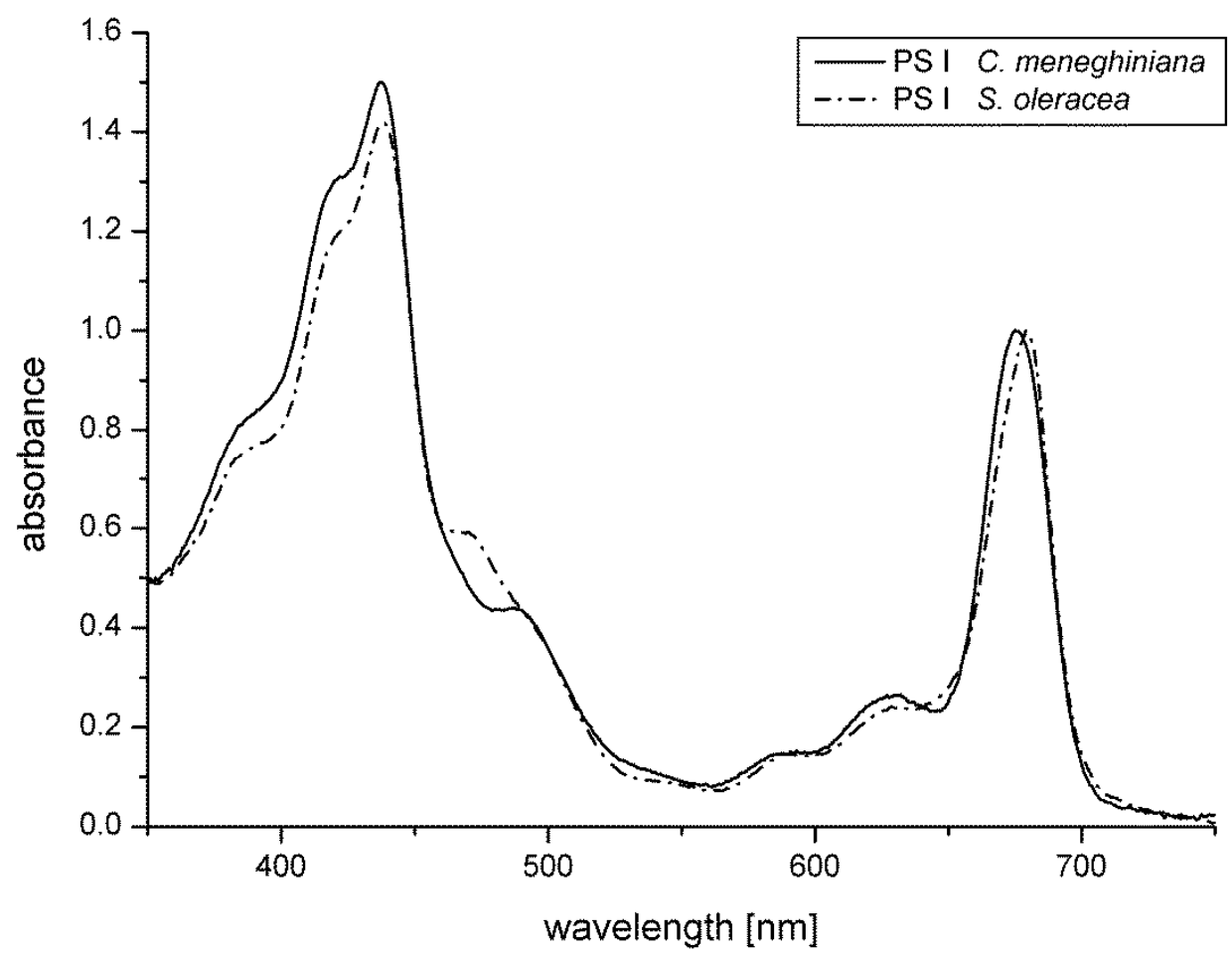

Figure 4: UV-VIS spectra: Comparison of absorption characteristics of solubilized PSI complexes from the green plant S. oleracea (dashed line) and the diatom C. meneghiniana (solid line). 


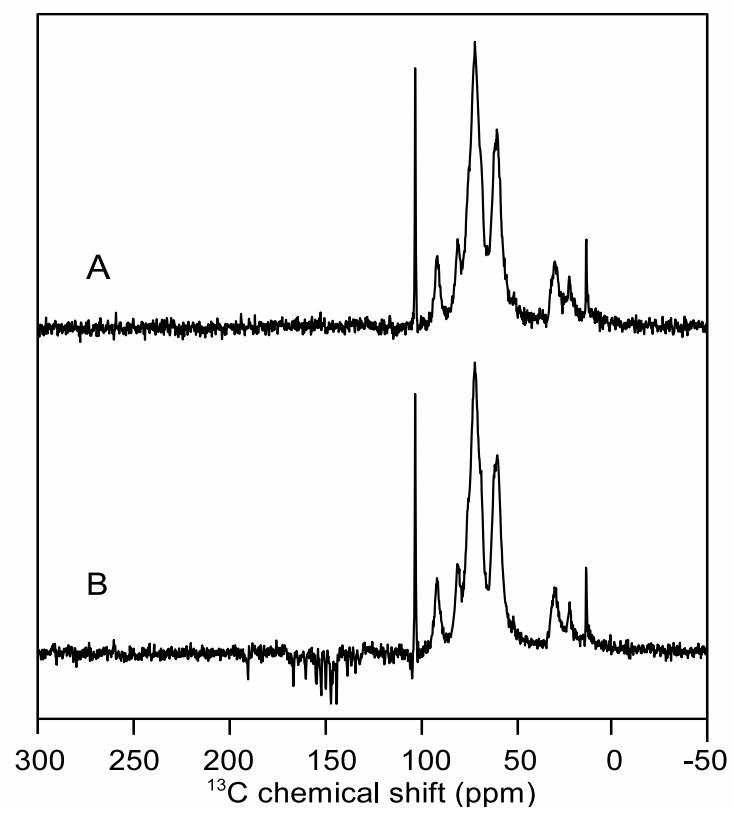

Figure 5: MAS NMR spectra of the PS I core complex from C. meneghiniana obtained in the dark (A) and under continuous illumination (B). The spectra have been obtained at a magnetic field of $9.4 \mathrm{Tesla}$, a temperature of $250 \mathrm{~K}$ and a MAS rotational frequency of $8 \mathrm{kHz}$.

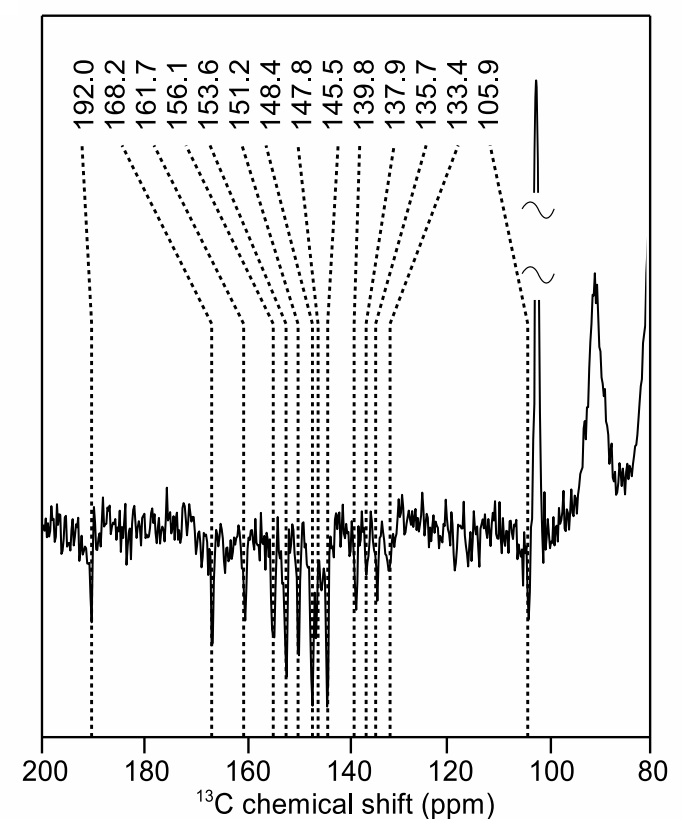

Figure 6: Photo-CIDNP MAS NMR spectrum of the PS I core complex from C. meneghiniana obtained under continuous illumination. Detailed view on the carbonylic and aromatic spectral region. 


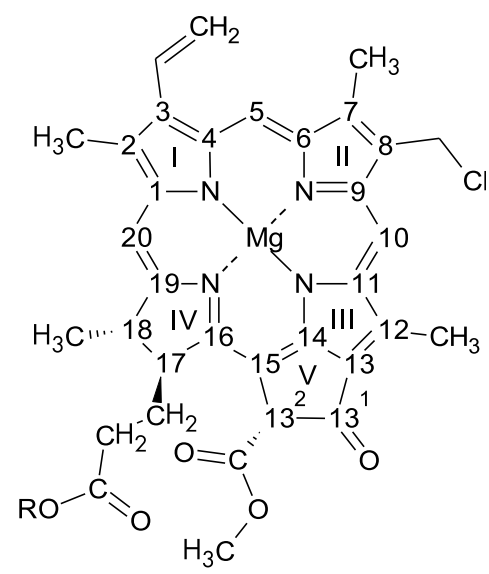

Figure 7: Molecular structure of $\mathrm{Chl}$ a with numbering according to IUPAC; $\mathrm{R}=$ Phytyl side chain.

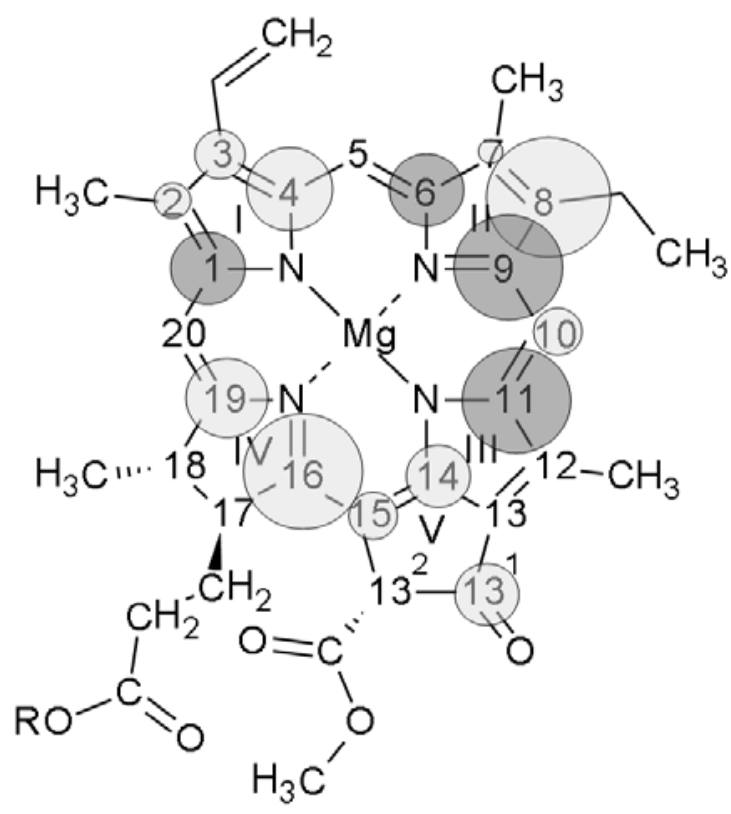

Figure 8: Photo-CIDNP patterns of $\mathrm{Chl}$ a molecules observed by ${ }^{13} \mathrm{C}$ photo-CIDNP MAS NMR in PS I core complexes of $C$. meneghiniana. The size of the circles is semiquantitatively related to the NMR intensities. Light grey circles are attributed to one carbon position only. Dark grey circles are attributed to two carbon positions. The observed pattern is very similar to the one observed from S. oleracea.[20] 
Table 1: Taxonomic overview of species in which the solid-state photo-CIDNP effect has been observed. For taxonomic relations see refs. [28] [79].

\begin{tabular}{|c|c|c|c|c|c|c|c|c|}
\hline Species & Genus. & Family & Order & Class & Phylum & Kingdom & Domain & $\begin{array}{l}\text { photo-CIDNP } \\
\text { MAS NMR }\end{array}$ \\
\hline $\begin{array}{l}\text { Heliobacillus } \\
\text { mobilis }\end{array}$ & $\begin{array}{l}\text { Helio- } \\
\text { bacillus }\end{array}$ & $\begin{array}{l}\text { Heliobacter- } \\
\text { iaceae }\end{array}$ & $\begin{array}{l}\text { Chlostridia- } \\
\text { les }\end{array}$ & Chlostridia & Firmicutes & Bacteria & $\begin{array}{l}\text { Prokary- } \\
\text { ota }\end{array}$ & ${ }^{13} \mathrm{C}[18]$ \\
\hline $\begin{array}{l}\text { Rhodopseu- } \\
\text { domonas } \\
\text { acidophilia }\end{array}$ & $\begin{array}{l}\text { Rhodo- } \\
\text { blastus }\end{array}$ & $\begin{array}{l}\text { Bradyrhizo- } \\
\text { biaceae }\end{array}$ & Rhizobiales & $\begin{array}{l}\text { Alphaproteo- } \\
\text { bacteria }\end{array}$ & $\begin{array}{l}\text { Proteobac- } \\
\text { teria }\end{array}$ & Bacteria & $\begin{array}{l}\text { Prokary- } \\
\text { ota }\end{array}$ & ${ }^{13} \mathrm{C}[15]$ \\
\hline $\begin{array}{l}\text { Rhodobacter } \\
\text { sphaeroides }\end{array}$ & $\begin{array}{l}\text { Rhodo- } \\
\text { bacter }\end{array}$ & $\begin{array}{l}\text { Rhodobac- } \\
\text { teraceae }\end{array}$ & $\begin{array}{l}\text { Rhodobac- } \\
\text { terales }\end{array}$ & $\begin{array}{l}\text { Alphaproteo- } \\
\text { bacteria }\end{array}$ & $\begin{array}{l}\text { Proteobac- } \\
\text { teria }\end{array}$ & Bacteria & $\begin{array}{l}\text { Prokary- } \\
\text { ota }\end{array}$ & $\begin{array}{l}{ }^{13} \mathrm{C}[3][9] \\
{ }^{15} \mathrm{~N}[14]\end{array}$ \\
\hline $\begin{array}{l}\text { Synechocyst- } \\
\text { is } s p .\end{array}$ & $\begin{array}{l}\text { Synecho- } \\
\text { cystis }\end{array}$ & & $\begin{array}{l}\text { Croococca- } \\
\text { les }\end{array}$ & $\begin{array}{l}\text { Oszillatorio- } \\
\text { phycideae }\end{array}$ & $\begin{array}{l}\text { Cyanobac- } \\
\text { teria }\end{array}$ & Bacteria & $\begin{array}{l}\text { Prokary- } \\
\text { ota }\end{array}$ & ${ }^{13} \mathrm{C}[17]$ \\
\hline $\begin{array}{l}\text { Chlorobium } \\
\text { tepidum }\end{array}$ & $\begin{array}{l}\text { Chloroba- } \\
\text { culum }\end{array}$ & $\begin{array}{l}\text { Chlorobia- } \\
\text { ceae }\end{array}$ & Chlorobiales & Chlorobia & Chlorobi & Bacteria & $\begin{array}{l}\text { Prokary- } \\
\text { ota }\end{array}$ & ${ }^{13} \mathrm{C}[16]$ \\
\hline $\begin{array}{l}\text { Chlamydo- } \\
\text { monas rein- } \\
\text { hardtii (LOV) }\end{array}$ & $\begin{array}{l}\text { Chlamy- } \\
\text { domonas }\end{array}$ & $\begin{array}{l}\text { Chlamydo- } \\
\text { monada- } \\
\text { ceae }\end{array}$ & $\begin{array}{l}\text { Chlamydo- } \\
\text { monadales }\end{array}$ & $\begin{array}{l}\text { Chlorophy- } \\
\text { ceae }\end{array}$ & Chlorophyta & Plantae & Eukaryota & ${ }^{13} \mathrm{C}[24]$ \\
\hline $\begin{array}{l}\text { Spirodela } \\
\text { oligorrhiza }\end{array}$ & Landoltia & Araceae & Alismatales & Liliopsida & Streptophyta & Plantae & Eukaryota & ${ }^{13} \mathrm{C}[80],{ }^{15} \mathrm{~N}[23]$ \\
\hline $\begin{array}{l}\text { Spinacia } \\
\text { oleracea }\end{array}$ & Spinacia & $\begin{array}{l}\text { Amarantha- } \\
\text { ceae }\end{array}$ & $\begin{array}{l}\text { Caryophyl- } \\
\text { la-les }\end{array}$ & & Streptophyta & Plantae & Eukaryota & $\begin{array}{l}{ }^{13} \mathrm{C}[20][21][22] \\
{ }^{15} \mathrm{~N}[23]\end{array}$ \\
\hline $\begin{array}{l}\text { C. mene- } \\
\text { ghiniana }\end{array}$ & Cyclotella & $\begin{array}{l}\text { Stephano- } \\
\text { discaceae }\end{array}$ & $\begin{array}{l}\text { Stephano- } \\
\text { discales }\end{array}$ & $\begin{array}{l}\text { Medio- } \\
\text { phyceae }\end{array}$ & $\begin{array}{l}\text { Bacillario- } \\
\text { phyta }\end{array}$ & Chromista & Eukaryota & this work \\
\hline
\end{tabular}


Table $2:{ }^{13} \mathrm{C}$ chemical shifts (ppm) of the photo-CIDNP MAS NMR signals in comparison to published chemical shift data of Chl a.

\begin{tabular}{|c|c|c|c|c|c|}
\hline $\begin{array}{l}{ }^{13} \mathrm{C} \text { chemical shift } \\
(\mathrm{ppm})^{\mathrm{a}}\end{array}$ & $\begin{array}{l}\text { tentative assign- } \\
\text { ment, carbon num- } \\
\text { ber according to } \\
\text { IUPAC }\end{array}$ & $\begin{array}{l}{ }^{13} \mathrm{C} \text { chemical shift } \\
(\mathrm{ppm})^{\mathrm{b}}\end{array}$ & $\begin{array}{l}{ }^{13} \mathrm{C} \text { chemical shift } \\
(\mathrm{ppm})^{\mathrm{c}}\end{array}$ & $\begin{array}{l}{ }^{13} \mathrm{C} \text { chemical shift } \\
(\mathrm{ppm})^{\mathrm{d}}\end{array}$ & $\begin{array}{l}{ }^{13} \mathrm{C} \text { chemical shift } \\
(\mathrm{ppm})^{\mathrm{e}}\end{array}$ \\
\hline $192.0(\mathrm{E})$ & $13^{1}$ & 190.6 & 190.6 & & 189.5 \\
\hline $168.2(E)$ & 19 & 170.0 & $167.1(\mathrm{E})$ & 166.9 & 168.0 \\
\hline $161.7(E)$ & 14 & 162.0 & $160.4(E)$ & & 162.1 \\
\hline $156.1(\mathrm{E})$ (broad) & 1 and 6 & 155.9 and 154.4 & $154.8(\mathrm{E})$ & 154.8 and 149.8 & 154.2 \\
\hline $153.6(E)$ & 16 & 154.0 & $152.6(\mathrm{E})$ & & 155.4 \\
\hline $151.2(E)$ & 4 & 150.7 & $149.9(\mathrm{E})$ & & 147.9 \\
\hline $148.4(E)(147.8)$ & 9 and 11 & 147.2 and 147.2 & $147.2(\mathrm{E})$ & 147.6 & $146.1(147.8)$ \\
\hline $145.5(E)$ & 8 & 146.2 & $144.2(\mathrm{E})$ & 144.2 & 144.1 \\
\hline $139.8(E)$ & 3 & 137.0 & $138.6(E)$ & 138.6 & 139.1 \\
\hline $137.9(\mathrm{E})$ & 2 & 136.1 & $\sim 136(E)$ & & 135.5 \\
\hline $135.7(E)$ & 12 & 134.0 & - & & 134.2 \\
\hline \multirow[t]{2}{*}{$133.4(E)$ (broad) } & 7 & 133.4 & $\sim 132(E)$ & & 134.0 \\
\hline & 13 & & & 128.3 & \\
\hline $105.9(E)$ & 10 and 15 & 108.2 and 102.8 & $105.4(E)$ & 104.5 & $107.3(106.2)$ \\
\hline
\end{tabular}
(a) this work.
(b) isolated Chl $a$ as solid aggregate, ref. [66].
(c) observed in PS I from spinach (Spinacia oleracea), ref. [20].
(d) data obtained from hole cells (PS I and PS II) from Synechocystis sp. PCC 6803, ref.[17].
(e) Chl a' dissolved in tetrahydrofuran- $\mathrm{d}_{8}$ ref. [75].

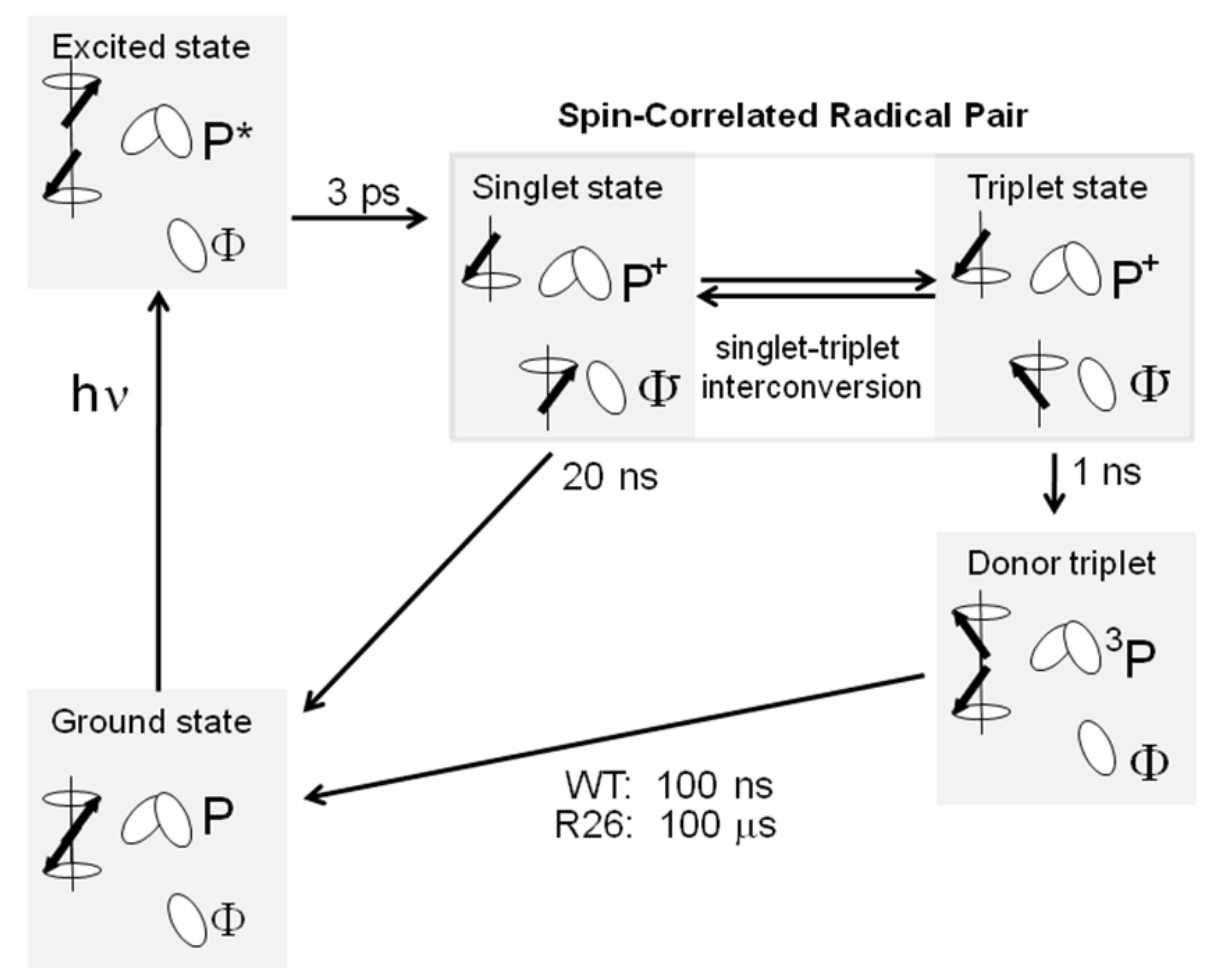

Scheme 1: Electron transport pathways in quinone-blocked bacterial RCs of $R$. sphaeroides WT and the carotene-less mutant R26.[81] 